\title{
Elaboration of Microspheres' Capsules Based on Ethylcellulose and Synthesized Poly (Butylsuccinate) as Biodegradable Matrices for Drug Delivery of an Antithyroidian Agent
}

\author{
Soumia Chirani ${ }^{1,2}$, Mohamed Oussama Lebig', Sarah Bouameur ${ }^{2,3}$, Meriyem Mouffok', Naziha \\ Chirani $^{4,5}$, Nafa Chafi ${ }^{\star 1,4}$, Kaddour Guemra ${ }^{1,4}$ \\ ${ }^{1}$ Laboratory of Organic Physical and Macromolecular Chemistry, Faculty of Exact Sciences, University DjillaliLiabes of SidiBel-Abbes, \\ ALGERIA. \\ ${ }^{2}$ Department of Pharmacy, Faculty of Medicine Sciences, University DjillaliLiabes of SidiBel-Abbes, ALGERIA. \\ ${ }^{3}$ Hospitalo-Universitary Center C.H.U of Sidi Bel-Abbes, 22000 ALGÉRIA. \\ ${ }^{4}$ Department of Chemistry, Faculty of Exact Sciences, University DjillaliLiabes of SidiBel-Abbes, ALGERIA. \\ ${ }^{5}$ Laboratory of Innovation and BioperformanceAnalyse -LIAB, Polytechnic School, University of Montreal Quebec, CANADA.
}

\begin{abstract}
Introduction: The present paper provides details of preparation of hardcapsules based on microspheres containing 2-aminothiazole as an antithyroidian agent and synthesized poly(butylsuccinate) (PBS) or ethylcellulose(EC10) as biodegradable matrices as well as the study of the drug delivery. Methods: A disintegration tests of these gelatinous capsules were done. The biodegradable synthesized polyester was characterized by infrared spectroscopy, nuclear magnetic resonance (mono and bidimentional H1NMR, $13 \mathrm{CNMR}$ ) and by Differential Scanning Calorimetry (DSC). A viscosimetric study has been done in order to evaluate viscosimetric PBS's weight wich was calculated from Mark-Houwink equation. The microencapsulation of 2-aminothiazole was done using solvent evaporation technique. Results: Microspheres were spherical and the effects of varying emulsifiers and blades number on microspheres encapsulation efficiency were evaluated. A kinetic studies of releases of 2-aminothiazole in gastric $\mathrm{pH}$ were done in order to evaluate the best late effect and then the best formulation.
\end{abstract}

Key words: Antithyroidian agent, Microspheres, Biodegradable polymer matrix, Capsules, Drug release, Kinetic study.

\section{INTRODUCTION}

Antithyroid drugs (ATD) have long been used for the drug therapy of graves' disease ${ }^{1}$ 2-Aminithiazole is among the first synthesized antithyroid drugs. It inhibits thyroperoxydase that catalyzes iodination and thyroid hormone biosynthesis.

Biodegradable polyesters and co-polyesters have been the focus of extensive research for several decades as a result of their ease of manufacturing and desirable characteristics. A long with the appropriate physical and mechanical properties, the biocompatibility of degradable polymers and their degradation products play an important role in determining their potential applications. ${ }^{2}$ Then, their ranges of physical properties and hydrolytic degradation profiles have made them attractive candidates for human use as surgical sutures, implantable devices, and drug delivery systems by the US Food and Drug Administration (FDA). ${ }^{3-8}$ The biocompatibilities of various biodegradable polymers such as poly( $\alpha$-hydroxyesters), polyanhydrides and poly(anhydride-co-imides) as candidate materials for various biomedical applications have been extensively investigated. ${ }^{9-11}$
Submission Date: 21-03-2016; Revision Date: 06-06-2016; Accepted Date: 17-11-2016

DOI: 10.5530/ijper.51.2s.53 Correspondence: Prof. Nafa Chafi, Laboratory of Organic Physical and Macromolecular Chemistry, Faculty of Exact Sciences, University Djillali Liabes of SidiBel-Abbes, BP 89 Larbi Ben M'HIDI City, Sidi Bel Abbes 22000 ALGERIA.

Ph.no: +213771735887

E-mail: nafachafi@yahoo.com

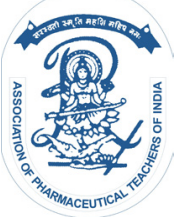

www.ijper.org 
Aliphatic polyester polymers degrade in to non-toxic monomers by bulk hydrolysis of the ester bonds, then avoiding the need for surgical removal so the risk of long term toxicity or a probable immunological reaction when compared with non degradable systems is also minimized. ${ }^{12}$

Micro-encapsulation is a method of fabricating materials with valuable new properties in the pharmaceutical industry ${ }^{13,14}$ and other fields; $;^{15-17}$ it is one of the quality preservation techniques of sensitive substances. In current pharmacology, micro-encapsulation is employed as a masking technique and, in particular, to control and modify drug release. Further, microspheres formulated from biodegradable polymers are interesting for sustained drug delivery of pharmaceuticals. ${ }^{18}$

Initially, in our research, we were focused on aliphatic polyesters because of their physical properties and nontoxic hydrolytic degradation; then we havesynthesized and characterized biodegradable matrix:

Poly (buthylsuccinate) (PBS) and evaluated its viscosimetric weight using Mark-Houwink equation. The solvent evaporation technique of micro-encapsulation was used for the preparation of solid microspheres based on our synthesized PBS and ethylcellulose as a matrices and 2-aminothiazole as an antithyroid agent. Ethycellulose was used as matrix polymer in which drug was dispersed because of its biodegradability and hydrophobic characteristic. The method is based on an oil-in-water $(\mathrm{O} / \mathrm{W})$ emulsion followed by solvent evaporation which leads to monolithic systems known as microspheres. ${ }^{19}$ This technique has been the method most commonly used to prepare controlled-release pharmaceuticals. ${ }^{20-23}$ We have chosen to our microspheres a gelatinous capsules as a solid oral pharmaceutical form according to the European pharmacopeia. ${ }^{25}$ In order to prove the best formulation a kinetic studies of drug delivery in reconstituted gastric media was done and then several release rates were evaluated and mathematically modeled to determine the release mechanism.

\section{MATERIALS AND METHODS}

The IR spectrum of PBS was obtained on Schimadzu FTIR-83 instument on 1\% potassium bromide disks. Its ${ }^{1} \mathrm{H}$ NMR, RMN 2D (cosy $\left.{ }^{1} \mathrm{H}-{ }^{1} \mathrm{H}\right)$ and ${ }^{13} \mathrm{C}$ NMR spectra were obtained at the University of Rennes-1 (in France) on a bruker WM500. The differential scanning calorimetry (DSC)'s spectrum of PBS was recorded on a setraram DSC apparatus at Rennes-1 University (Pr J. F. Carpentier Services, UMR 6226 CNRS). Molecular weight of our polyester was obtained using a cappilary viscosimeter: Thermovisc 100-B125 (Ubbelhode) instrument.

Microparticles were prepared in a cylindrical glass reactor (volume of $600 \mathrm{~mL}$, external diameter $=80 \mathrm{~mm}$ ) with six and four-bladed turbine impellers (type Velp Scientific as.r.l ISO 9001, ISO 14001; Italy) plunged in a bath adjusted to $25^{\circ} \mathrm{C}$; (blade length $=12 \mathrm{~mm}$ for six blades and $18 \mathrm{~mm}$ for the fourth one; blade width=10 $\mathrm{mm}$ )

The mean diameters and size distribution of micro particles were calculated from results of optical microscopy (Optika zoom stereo microscopes SZM).

The filling of capsules was done using a semi-automatic filler machine type CAPSUNORM®2000, TECNYFARMA GROUPE in Laboratory of Galenical Pharmacy in the Department of Pharmacy of the Faculty of Medical Sciences of the Djillali liabes University of Sidi Bel-Abbes in Algeria.

\section{Synthesis of poly (buthylsuccinate) (PBS)}

It was successfully done by the application of the "ring opening polymerisation" 24

A mixture of buthan1,4diol ( $0.12 \mathrm{~mol}$.) and succinic acid ( 0.10 mol.) in presence of catalytic amount of 1 to $2 \%$ of titaneisopropoxide was refluxed during two hours at $180^{\circ} \mathrm{C}$ with high stirring under a nitrogen draught. In order to purify the obtained polymer (to eliminate residual monomers) it was heated at $200^{\circ} \mathrm{C}$ under reduced pressure $\left(\mathrm{max}=10^{-3} \mathrm{mmHg}\right)$ during three hours.

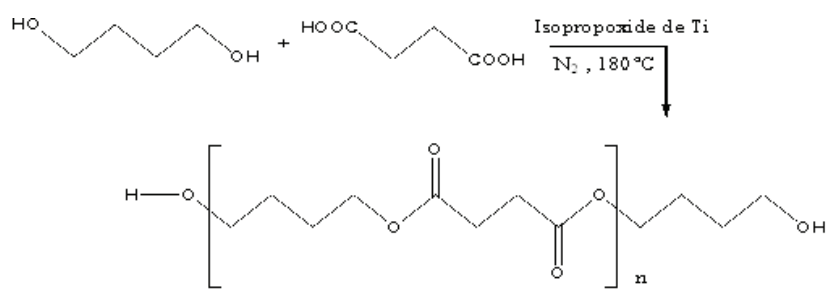

\section{Microspheres preparation}

The monolithic systems were obtained by the emulsion solvent diffusion method using de-ionized water as an external phase in which $0.5 \%$ of the emulsifier (PVA or Tween 80 ) was dissolved. The internal phase was composed of 2-aminothiazole with EC or PBS as matrices $(2$-aminothiazole $/$ matrix $=50$ mass $\%$ ) and dichloromethane (DCM) as the organic solvent (polymer matrix $/ \mathrm{DCM}=6$ mass $\%$ ).

First, the drug and polymer were co-dissolved in the organic solvent by heating them under slight reflux $\left(30-35^{\circ} \mathrm{C}\right)$ and stirred to get homogenization. At the same time, the emulsifier was dissolved in $250 \mathrm{~g}$ of deionized water under heating and stirring. After cooling to laboratory temperature, the organic phase was emulsified with the continuous phase under mechanical 
stirring $(600 \mathrm{rpm})$ for $3 \mathrm{~h}$ to complete solvent evaporation. Then, the dispersion was filtered and microspheres were vacum-dried in a desiccator in the presence of $\mathrm{CaCl}_{2}$.

\section{Filling of microspheres in gelatin capsules}

We have chosen gelatin capsules as a solid oral pharmaceutical form for our elaborated microspheres because of its disponibility and its ease of development. Then, in the first we've determined the appearent volume of microspheres to determine the capsules size as well as the volume of diluent ${ }^{25}$ We have determined diluent volumes (lactose orsaccharose) using the Table 1 which gives the total volume of the capsule too.

However, we gave for each formulation of microspheres: the appearent volume, the number of capsule and the diluent volume.

\section{Drug release study}

The release kinetic studies of the active agent from microspheres were performed in a cylindrical doublewall glass reactor $(100 \mathrm{~mL})$, kept at a temperature of $(37 \pm 0.5)^{\circ} \mathrm{C} .100 \mathrm{mg}$ of microspheres were dispersed in $100 \mathrm{~mL}$ of simulated gastric medium $(\mathrm{pH} \mathrm{1,2})$. The dissolution medium was stirred magnetically at a rotation speed of $500 \mathrm{~min}^{-1}$ to achieve good homogenization. A sink method was followed: Samples $(3 \mathrm{~mL})$ of the solution were collected for analysis at different time intervals and replaced simultaneously by $3 \mathrm{ml}$ of the gastric $\mathrm{pH}$. The samples were analyzed using a UV-VIS spectrophotometer at $\lambda_{\max }=268 \mathrm{~nm}$ of 2 -Aminothiazole. The value of molar extinction co-efficient $\varepsilon_{\max }\left(1 . \mathrm{mole}^{-1}\right.$. $\left.\mathrm{cm}^{-1}\right)=3038$ is calculated from the slope of the plot of Abs $=\mathrm{f}(\mathrm{C})$ at $\mathrm{pH}=1.2$.

The release studies were carried out in a buffered solution at $\mathrm{pH} 1.2$ and $37^{\circ} \mathrm{C}$ and the influence of the matrix on the ATD's release was studied.

\section{RESULTS}

\section{Poly (buthylsuccinate) characterization}

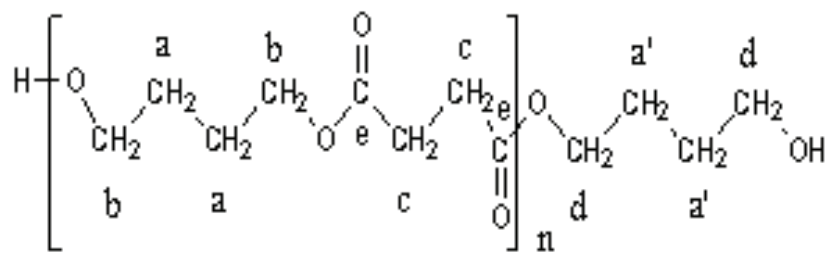

- From the ${ }^{1} \mathrm{H}$ NMR spectra of poly (buthylsuccinate) (Figure. 1) we confirmed $\delta \mathrm{H}\left(\mathrm{CDCl}_{3}\right)$ (ppm): 1.65 $\left(\mathrm{CH}_{2}(\mathrm{a})\right) ; 1.55\left(\mathrm{CH}_{2}\left(\mathrm{a}^{\prime}\right)\right) ; 2.55\left(\mathrm{CH}_{2}(\mathrm{c})\right) ; 4.05\left(\mathrm{CH}_{2}\right.$ (b)) $; 3.55\left(\mathrm{CH}_{2}(\mathrm{~d})\right)$.

- 2D NMR ( $\left.\operatorname{cosy}^{1} \mathrm{H}-{ }^{1} \mathrm{H}, \mathrm{CDCl}_{3}, 500 \mathrm{Mhz}\right)$ of poly (buthylsuccinate) was done (Figure. 2)

\begin{tabular}{|l|c|c|c|c|c|c|c|c|}
\hline & Table 1: Approximate capacities of gelatin capsules \\
\hline & $\mathbf{0 0 0}$ & $\mathbf{0 0}$ & $\mathbf{0}$ & $\mathbf{1}$ & $\mathbf{2}$ & $\mathbf{3}$ & $\mathbf{4}$ & $\mathbf{5}$ \\
\cline { 2 - 9 } & $\mathbf{0 0 0}$ & 0.70 & 0.50 & 0.40 & 0.30 & 0.20 & 0.125 \\
\hline
\end{tabular}

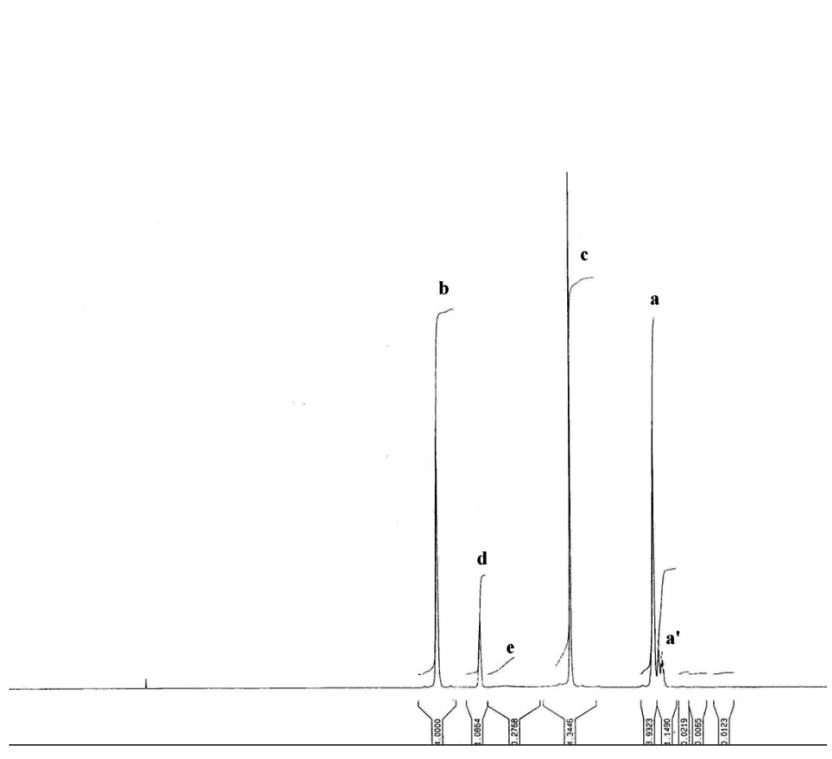

Figure 1: 1H NMR spectra of poly(buthylsuccinate)

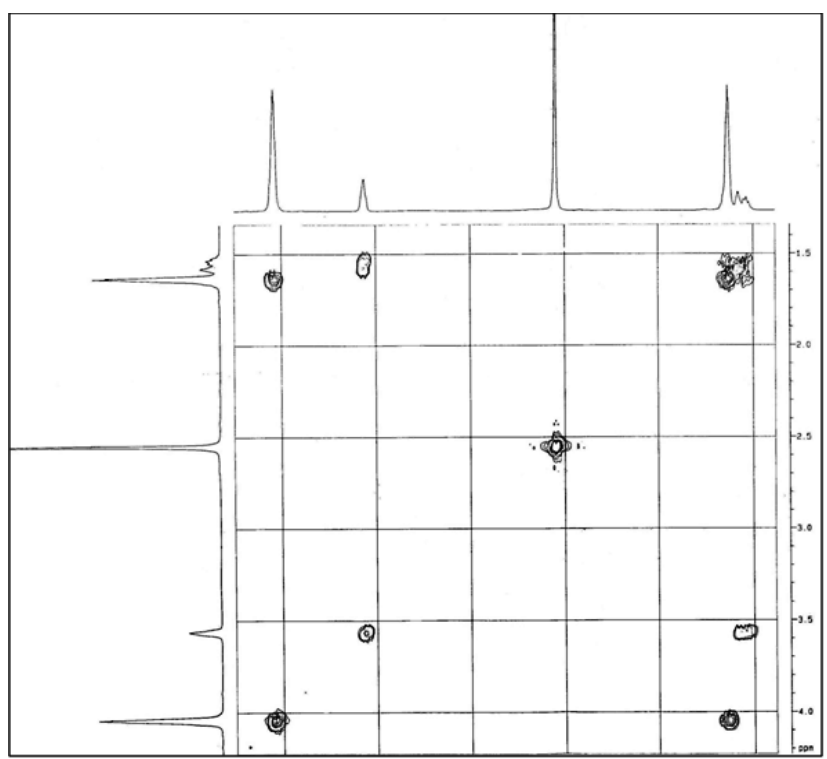

Figure 2: 2D NMR (cosy1H-1H, CDCl3, 500Mhz) of poly(buthylsuccinate) 
- FT-IR spectrum (Figure. 3) $(\mathrm{KBr}$ pellet) $\nu$ (cm-1): (1716-1732) (ester $\mathrm{C}=\mathrm{O})$; (2945-2956) $\left(\mathrm{CH}_{2}\right) ;(1100$ 1200) (ester C-O-C); (3429-3552) (terminal O-H).

- The glass temperature of our biopolymer was been picked on heating and cooling temperatures between 30 and $250^{\circ} \mathrm{C}$ on $10.4 \mathrm{mg}$ of PBS sample (Figure 4).

We used two "heating/cooling" cycles separated by 10 to $50^{\circ} \mathrm{C}$ bearing. The used speeds are $+10^{\circ} \mathrm{C} / \mathrm{mn}$ for heating and $-20^{\circ} \mathrm{C} / \mathrm{mn}$ for cooling.

The glass temperature depends on the speed; it's increased with heating/colding speed and it's the same with melting temprature. Exemple: $T_{f}$ PBS (colding) $>\mathrm{T}_{\mathrm{f}}$ PBS (heating). We note an average glass temperature $\operatorname{Tg}_{\mathrm{PBS}}=65^{\circ} \mathrm{C}$.

The heating and colding were been done under an argon atmosphere.

- Viscosimetric study of the polymer matrix (PBS) was done in chloroform at $\left(20^{\circ} \mathrm{C} \pm 1\right)$; the flow time of solvent was $\mathrm{t}_{0}=16.91 \mathrm{sec}$.

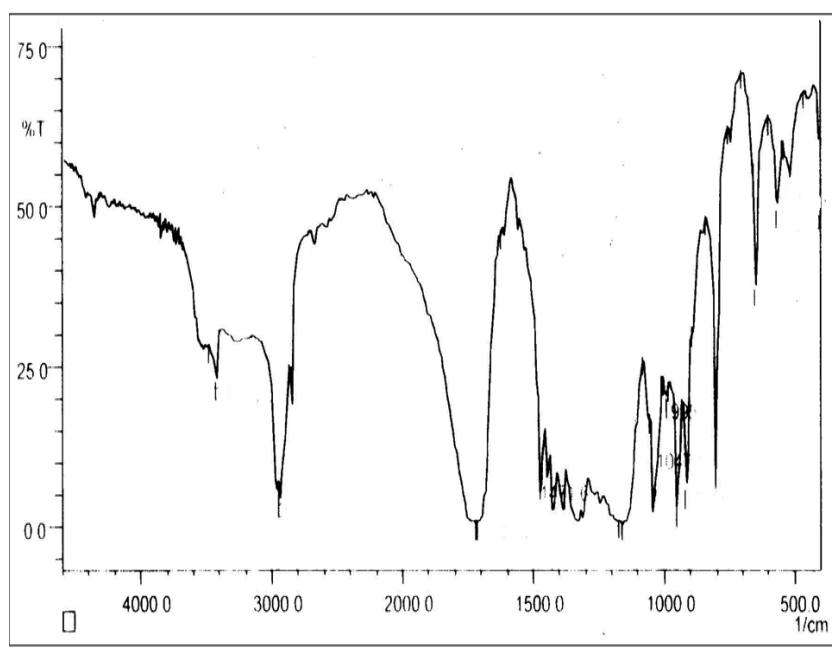

Figure 3: FTIR spectra of poly(buthylsuccinate)

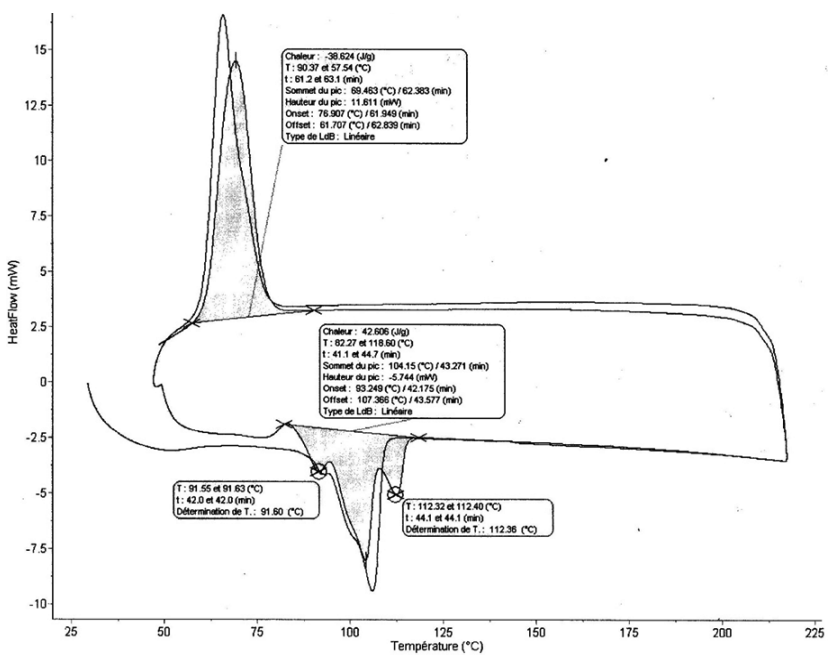

Figure 4: DSC thermogramme of poly(buthylsuccinate)

\section{Microparticles characterization}

The mean diameters and size distribution of microparticles were calculated from the results of optical microscopy (OPTIKA STEREOMICROSCOPES / SZM (SZM 1)), by counting more than 500 micro particles using appropriate lenses. Then, the classification of each microspheres' formulation was illustrated by the histograms shown in Figure 5.

The extractions of ATD agent from dried microparticles by absolute ethanol were performed in triplicate under stirring in sealed bottles for $24 \mathrm{~h}$ (Table 2).

The resulting solution was analyzed by UV-VIS spectroscopy (Shimadzu UV-2401 PC, Shimadzu, Japan) after an appropriate dilution with ethanol. The loading efficiency (2-aminothiazole loaded \%) and the encapsulation efficiency (Yield, \%) were calculated according to the following equations:

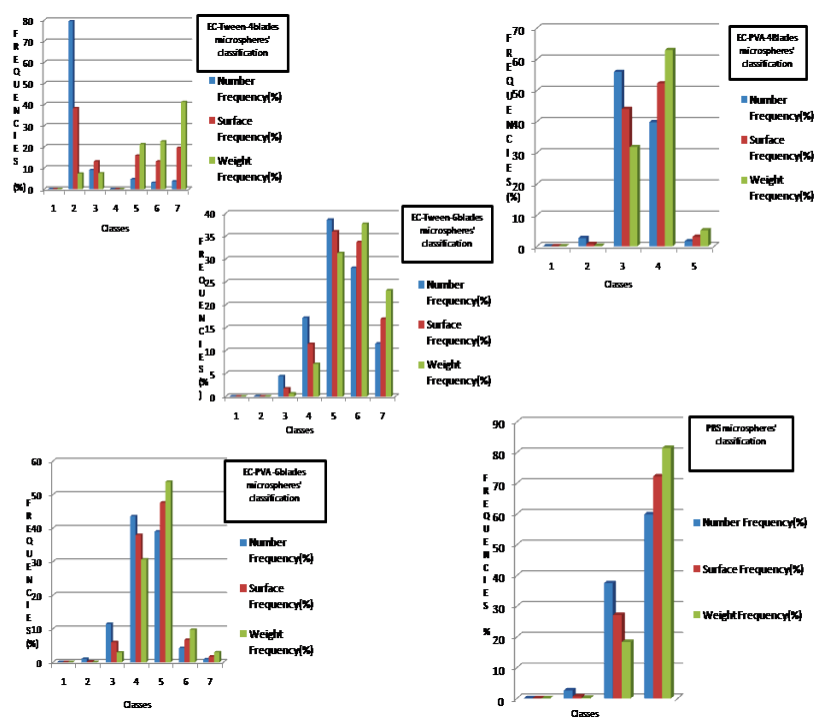

Figure 5: Classification of size distributions of all microspheres' formulations

\section{Table 2: Extractions of ATD agent from dried micro-} particles by absolute ethanol

\begin{tabular}{|c|c|c|}
\hline $\begin{array}{c}\text { Microspheres' } \\
\text { formulation }\end{array}$ & $\begin{array}{c}\text { Microspheres' } \\
\text { weight(mg) }\end{array}$ & $\begin{array}{c}\text { Absolute } \\
\text { ethanol'svolume }(\mathbf{m L})\end{array}$ \\
\hline PBS ${ }_{\text {microspheres }}$ & 10 & 20 \\
\hline $\mathrm{EC}_{\text {Tween-6blades }}$ & 10 & 50 \\
\hline $\mathrm{EC}_{\text {Tween-4blades }}$ & 15 & 10 \\
\hline $\mathrm{EC}_{\text {PVA-4Blades }}$ & 10 & 30 \\
\hline $\mathrm{EC}_{\text {PVA-6Blades }}$ & 10 & 50 \\
\hline
\end{tabular}


ATD loaded $=\frac{\text { mass of ATD in microparticles }}{\text { mass of microparticles }} \times 100$

$$
\text { Yield }=\frac{\text { mass of ATD in microparticles }}{\text { initial mass of ATD }} \times 100
$$

The microspheres were characterized by infrared spectroscopy and the infrared spectra of pure 2-aminothiazole,
EC, PBS and corresponding microparticles so obtained were compared. The FTIR spectra were recorded from $500 \mathrm{~cm}^{-1}$ to $4000 \mathrm{~cm}^{-1}$ using a Bruker FTIR ALPHA Spectrometer.

\section{Capsules filling}

Using the European Pharmacopea, we gave for each formulation of microspheres (Table 4$)^{25}$ the appearing volumes, the number of capsule and the diluent volumes.

\begin{tabular}{|c|c|c|c|c|c|c|}
\hline \multicolumn{7}{|c|}{ Table 3: Microparticle characteristics and encapsulation results } \\
\hline Microparticles & $\mathbf{d}_{\mathbf{1 0}}(\boldsymbol{\mu} \mathbf{m})$ & $\mathbf{d}_{\mathbf{3 2}}(\boldsymbol{\mu m})$ & $\mathbf{d}_{\mathbf{4 3}}(\boldsymbol{\mu m})$ & Dispersion $^{\mathbf{a}}$ & ATD $_{\text {loaded }}(\%)$ & Yield(\%) \\
\hline PBS & 27.69 & 33.24 & 34.70 & 1.25 & 14.70 & 16.90 \\
\hline EC $_{\text {Tween-6blades }}$ & 68.13 & 80.51 & 85.11 & 1.24 & 13.70 & 32.90 \\
\hline EC $_{\text {Tween-4blades }}$ & 05.96 & 26.10 & 41.80 & 7.01 & 12.40 & 16.10 \\
\hline EC $_{\text {PVA-4Blades }}$ & 70.00 & 70.00 & 70.00 & 1.00 & 15.23 & 21.88 \\
\hline EC $_{\text {PVA-6Blades }}$ & 51.00 & 61.90 & 65.80 & 1.29 & 14.74 & 25.40 \\
\hline
\end{tabular}

a) calculated as : the number mean diameter calculated as $\Sigma n_{i} d_{i} / \Sigma n_{i} ; d_{32}$ : the surface mean diameter calculated as $\Sigma n_{i} d_{i}^{3} / \Sigma n_{i} d_{i}^{2} ; d_{43}:$ the weight mean diameter calculated as $\Sigma n_{i} d_{i}^{4} / \Sigma n_{i} d_{i}^{3}$

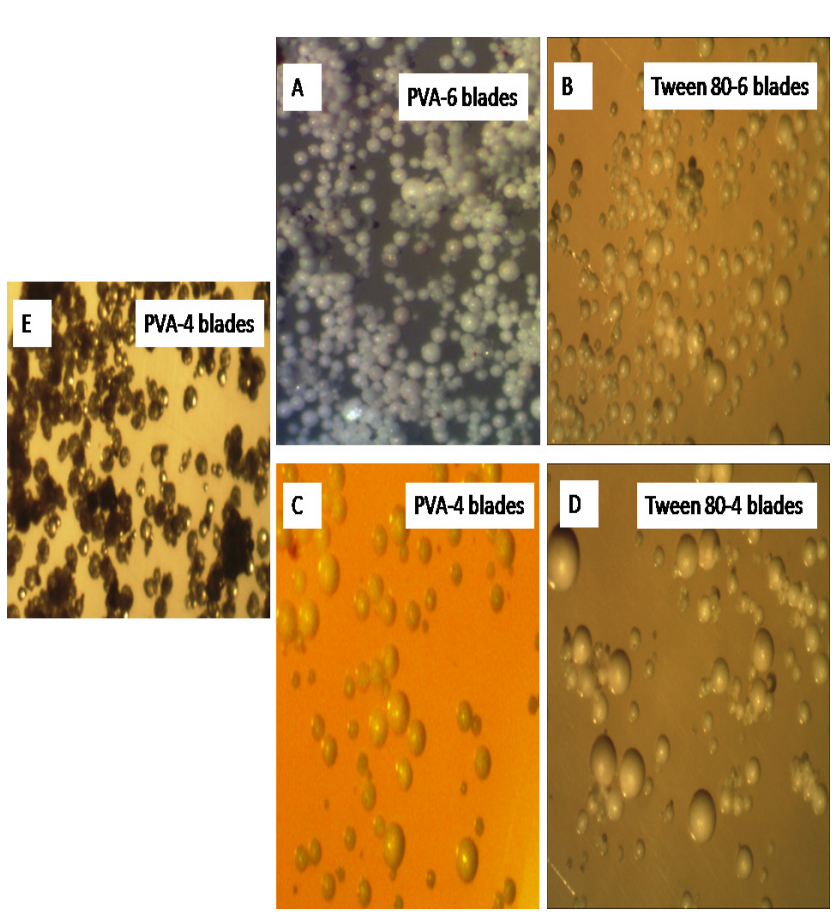

Figure 6: Microscopic images of 2-amiothiazole-loaded ethylcellulose's microparticles spherical form (A, B, C, D) and PBS one(E)

\begin{tabular}{|c|c|c|c|}
\hline \multicolumn{4}{|c|}{ Table 4: Parameters of microspheres' gelatin } \\
capsules \\
\hline mixture & $\begin{array}{c}\text { Appearent } \\
\text { Volume }(\mathrm{mL})\end{array}$ & Capsule $\mathbf{N}^{\circ}$ & $\begin{array}{c}\text { Diluent } \\
\text { Volume }(\mathbf{m L})\end{array}$ \\
\hline $\mathrm{EC}_{\text {Tween80-6blades }}$ & 1,1 & 000 & 0,26 \\
\hline $\mathrm{EC}_{\text {Tween80-4blades }}$ & 0,4 & 1 & 0,08 \\
\hline $\mathrm{EC}_{\text {PVA-4blades }}$ & 0,4 & 1 & 0,08 \\
\hline PBS $_{\text {PVA-4blades }}$ & 0,1 & 5 & 0,03 \\
\hline
\end{tabular}
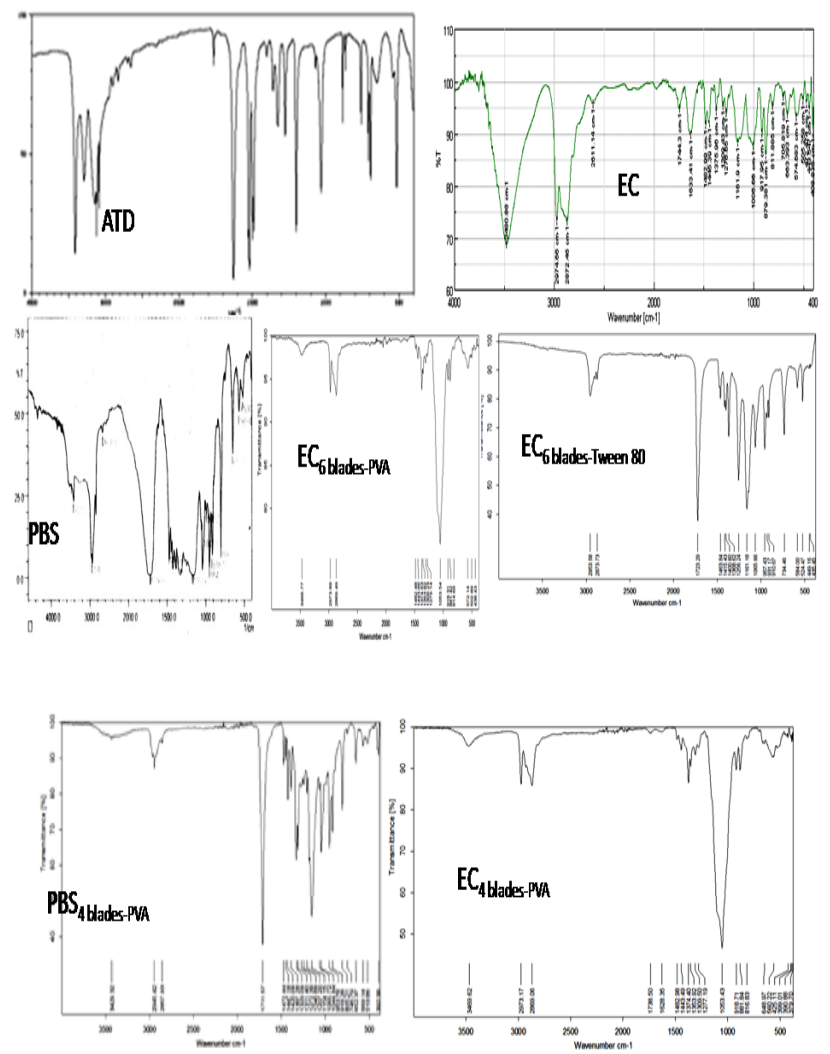

Figure 7: Infrareds pectra of the diffrent microparticles formulations, polymers matrices and 2-aminothiazole

\begin{tabular}{|c|c|c|}
\hline \multicolumn{3}{|c|}{ Table 5: Viscosimetric molecular weight of PBS } \\
\hline polymer & {$[\eta](\mathrm{ml} / \mathrm{g})(\mathbf{a})$} & $\mathbf{M v}(\mathbf{b})$ \\
\hline PBS & 8.445 & 1648 \\
\hline
\end{tabular}

where: (a) represents the intrinsec viscosity of the polyester measured in chloroform at $20^{\circ} \mathrm{C}$; and (b) the viscosimetric molecular weight of PBS calculated from MarkHouwink equation. 


\section{Drug release}

The disintegration tests of these gelatinous capsules improved that their degradation take few minutes $(4 \mathrm{mn})$; thing which allow us to consider and study directly the release from micro particles.

All formulations were seen to be intact throughout the dissolution studies. The percentage of drug released from microspheres relative to time is shown in Figure 8.

\section{DISCUSSION}

- The reduced viscosity of PBS was calculated using the next equation:

$$
\eta_{\mathrm{sp}}=\frac{\left(\mathrm{t}-\mathrm{t}_{0}\right)}{\mathrm{t}_{0}}
$$

and the Huggins equation

$$
\eta_{\text {red }}=\frac{\eta_{\text {sp }}}{C}=[\eta]+k_{H}[\eta]^{2}
$$

Where $\mathrm{t}$ and $\mathrm{t}_{0}$ are the flow times taken for polymer solution and solvent respectively and $\mathrm{C}$ is the concentration $(\mathrm{g} / \mathrm{cc})$ of solution.

In chloroform solution our polymer has a regular viscosimetric behaviour in a concentration interval from $10^{-3}$ to $10^{-2} \mathrm{~g} / \mathrm{cc}$.

Since the $[\eta]$ is directly proportional to the molecular weight of the polymer by Mark Houwink equation,

$$
[\eta]=K \cdot \overline{M_{v}^{a}}
$$

Where $\mathrm{k}$ and a are constants depends on solvent, polymer and conditions

Therefore

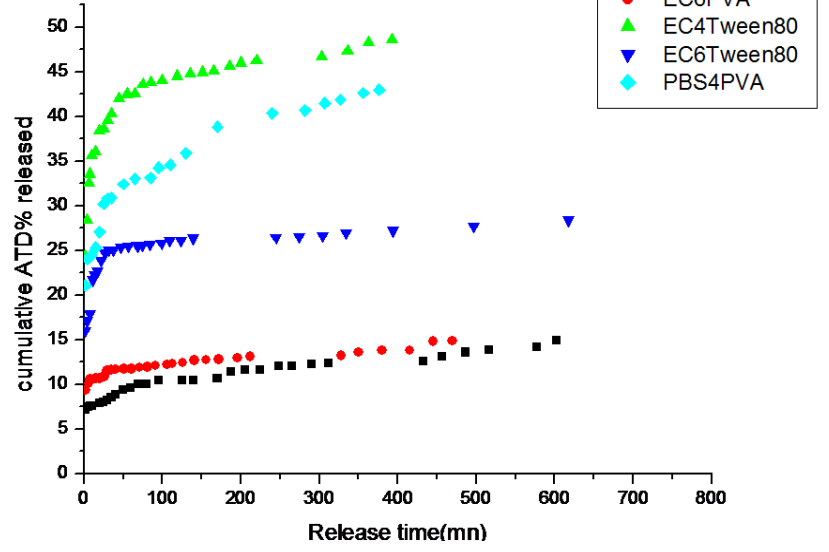

Figure 8: Cumulative release of ATD\% from the different microspheres in $\mathrm{pH}=1.2$ at $37^{\circ} \mathrm{C}$

\section{$[\eta] \alpha \overline{\mathrm{Mv}}$}

For our polyester:

$\mathrm{k}=24.4 \times 10^{-3} \mathrm{~mL} / \mathrm{g}$ and $\mathrm{a}=0.79$ at $20^{\circ} \mathrm{C}$.

However the equation 5 will be:

$$
[\eta](\mathrm{dL} / \mathrm{g})=24.4 \times 10^{-3} \mathrm{M}_{\mathrm{v}} 0.7
$$

Then, intrinsec viscosity was been determined by extra polling (at a null concentration) the graphic representation of $\eta_{\text {red }}=\mathrm{f}(\mathrm{C})$ (Figure 9)

Therefore, Viscosimetric molecular weight of PBS is given in Table 5.

- By means of the optical microscope, the surface and morphology of the micro particles were characterised and the size and size distribution were determined. In Figure 7 we note that the populations of micro particles have a homogeneous spherical shape. Taking the micro particles forms into account, the micro particle mean diameter was measured and finally the number mean diameter, the weight mean diameter and the surface mean diameter were calculated by examining 500 micro particles for each formulation. The characteristics of micro particles including the mean diameter, the percentage of 2-aminotiazole-loaded micro particles and the encapsulation yield obtained by extractions are given in Table 3.

- In the IR spectra of the different micro particle's formulations with polymers matrices and pure 2-aminothiazole (Figure 9), we noted the presence of some significant IR bands of 2-aminothiazole in all microspheres formulations spectra at the same wave numbers.

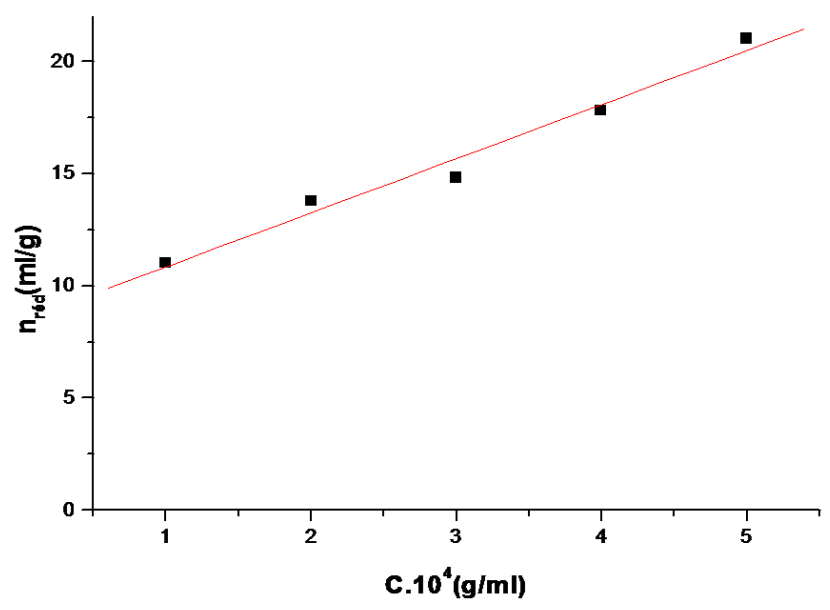

Figure 9: Evolution of reduced viscosity of PBS with concentrations 
However, we can consider that microspheres formu lations spectra as a sum of pure 2-aminothiazole and polymers matrices spectra. Then, the FTIR analysis confirms the presence of 2-aminothiazole in our different elaborated micro particles.

- We can deduce from the results (see Table 3) that microspheres elaborated from EC with PVA as emulsifier and using 4 blades are mono dispersed but not when increasing the number of blades $\left(\mathrm{EC}_{\mathrm{PVA}-\text {-6blades }}\right)$ where the dispersion increased with 0.29 degrees which is not so far but with Tween 80 and the same number of blades (4 blades) dispersion increased until 7.01 which is so worst. Also from the ATD loaded and the yield values we can deduce that the best formulation is well with the $\mathrm{EC}_{\mathrm{PVA}-\text {-blades }}$ (unitary convergence of dispersion, the best ATD loads and the best yield). However, the effect of the number of blades is weel marked. When about the PBS polymer matrix formulations, the only successful one is with PVA emusifier and four blades which was characterized with its good dispersion (1.25). Then the great effect of emulsifier can be explained by their chemical structures (Figure 10).

Moreover, the encapsulation with PBS has succeeded only with PVA and using 4 blades; which can be explained with emulsifiers chemical structures too as well as when increasing the number of blades microspheres eclated.

- From the drug releases studies we can notice the effect of: matrix, emulsifier and blade number (Figure 8) on the drug release from microspheres. The results demonstrated that in the case of EC as matrix and PVA as an emulsifier, the effect of blade number on the release of 2-Aminothiazole is not remarkable. However, its releases using the Tween 80 as an emulsifier depends largely on blade numbers: after $2 \mathrm{~h}$ (the time corresponding to the drug retention in the human stomach), the percentages of the drug released from EC4Tween 80 and EC6Tween 80 are $45 \%$ and 25\%, respectively. Then in this case when the number of blades increases the amount of the active agent released decreases; thing which can be explained by the structure of

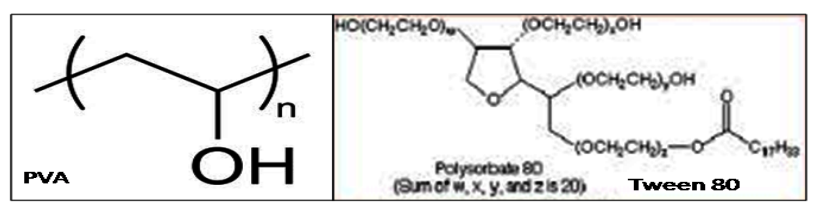

Figure 10: Emulsifiers structures
Tween 80 which favorites the formation of more microspheres if we increase the number of blades, then the release from the same pores of the same micro particle is slower than its release from different pores of several microspheres. Also, in the same conditions of emulsifier and blade numbers, the release from PBS's microspheres is faster than from EC's ones. It can be explained by the interactions between the polymer matrix and the enveloped molecules of 2-Aminothiazole due to their polarity as well as the size of micro particles $\left(\mathrm{d}_{32}\right)$. However, we have noted the significant effect of polymer type on microspheres sizes and the drug release rate from the obtained microspheres. Figure 8 shows that the cumulative release is more speed from the smaller microspheres prepared with PBS' $(33.14 \mu \mathrm{m})$ than the $\mathrm{EC}$ ones $(70.00 \mu \mathrm{m})$.It was reported that for the smaller microspheres, a larger effective area produces a greater number of drug molecules in the surface of the microspheres, which leading to a faster drug release. ${ }^{26-33}$

\section{Release mechanisms and mathematical analysis}

The mathematical description of drug diffusion is often based on Fick's second law. ${ }^{34}$ In the literature, many theoritical or empirical models are described to explain this process of mass transfer. In our study, we chose four of them for quantitative prediction of controlled drug delivery. The selected models are: the first order, the Higuchi's ${ }^{35}$ and the Hixson-Crowell's. ${ }^{36}$ Thus the choice of the best model is based on the value of $r^{2}$, correlation coefficient obtained after tracing experimental results according to the equations corresponding to the selected models.

\section{First Order}

$$
\log \mathrm{Q}_{\mathrm{t}}=\log \mathrm{Q}_{0}+\frac{\mathrm{K}_{1} \cdot \mathrm{t}}{2.303}
$$

\section{Higuchi}

$$
Q_{t} \quad K_{H} \sqrt{t}
$$

\section{Hixson-Crowell}

$$
\sqrt[3]{Q_{t}}-\sqrt[3]{Q_{r}}=K_{s} \cdot t
$$

Where $Q_{t}$ is the amount of drug dissolved in time t; $\mathrm{Q}_{0}$ is the initial amount of drug in the solution (most times $\left.\mathrm{Q}_{0}=0\right) ; \mathrm{Q}_{\mathrm{i}}$ is the initial amount of drug in the 
pharmaceutical dosage form; $\mathrm{Qr}$ is the amount of drug remaining as a solid state at time $t ; \mathrm{Mt} / \mathrm{M} \infty$ is the fraction of drug released; $\mathrm{K}_{1}, \mathrm{~K}_{\mathrm{H}}$ and $\mathrm{K}_{\mathrm{S}}$ are, respectively the first order, the Higuchi's and the Hixson-Crowell's release constants; and $n$ the release exponent that indicates of the mechanism of release..$^{35-40}$

The Hixson-Crowell model assumes that the drug release is limited by the dissolution rate of the particles, and not by diffusion through the polymer matrix, ${ }^{37}$ and the Higuchi model able to describe the release of soluble or poorly soluble drug in water from a semi-solid or solid matrix system. ${ }^{35}$ Therefore, the value of $\mathrm{n}$ was used by Peppas ${ }^{40}$ in order to characterize the various release mechanisms. When $\mathrm{n}=0.5$ the release mechanism as Fick diffusion, and as a non-Fickian model if $\mathrm{n}$ is between 0.5 and 1.0 or $n=1.0$. When $n=0.5$, the drug release is controlled by diffusion and is time-dependent while when $\mathrm{n}=1.0$, the drug release is controlled by

\section{Table 6: Coefficients of correlation and dissolution} rate constants of ATD from microspheres

\begin{tabular}{|c|c|c|c|c|}
\multirow{2}{*}{ Formulation } & \multicolumn{2}{|c|}{ Higuchi } & \multicolumn{2}{c|}{ Hixon-crowell } \\
\cline { 2 - 5 } & $\mathbf{r}^{2}$ & $\mathbf{K}_{\mathbf{H}}$ & $\mathbf{r}^{2}$ & $\mathbf{K}_{\mathbf{S}}$ \\
\hline PBS $_{\text {PVA-4 blades }}$ & 0.96509 & 0.69031 & 0.96929 & 4.63109 \\
\hline EC $_{\text {PVA-4 blades }}$ & 0.99343 & 0.17406 & 0.97698 & 02196 \\
\hline $\mathrm{EC}_{\text {PVA-6 blades }}$ & 0.965 & 0.39283 & 0.99800 & 1.11574 \\
\hline EC $_{\text {Tween80-4 blades }}$ & 0.9900 & 2.48058 & 0.98815 & 5.20217 \\
\hline EC $_{\text {Tween80-6 blades }}$ & 0.9844 & 2.12258 & 0.98752 & 5.19759 \\
\hline
\end{tabular}

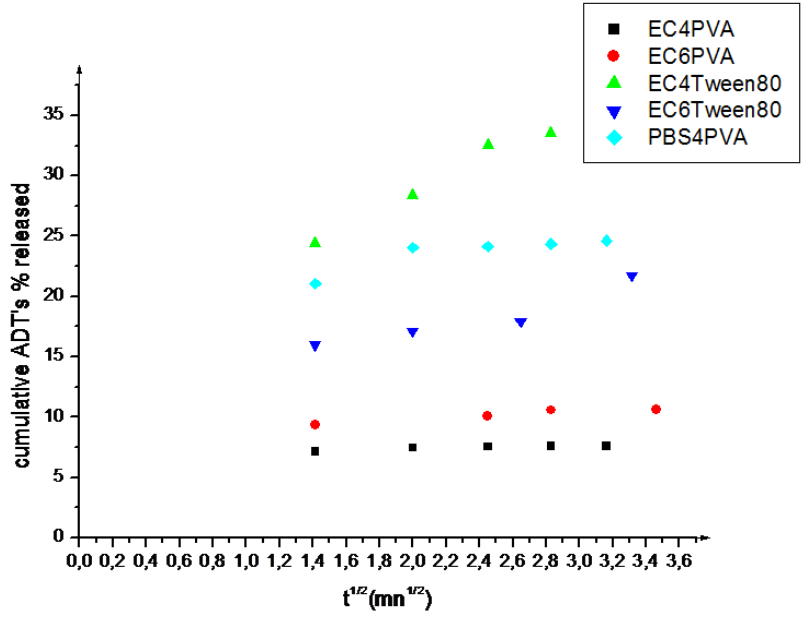

Figure 11: Higüchi plots of ATD\% released from microspheres in gastric $\mathrm{pH}$ at $37^{\circ} \mathrm{C}$ swelling and is time-independent with zero order kinetics. Values of $\mathrm{n}$ between 0.5 and 1.0 indicate superposition of both phenomena, known as anomalous transport. It is necessary to consider that the exponent values are valid for certain slab geometry, and different values can be derived for spheres and cylinders. ${ }^{34}$ The model which gave the highest coefficient of correlation $\mathrm{r}^{2}$ was considered to be the most suitable kinetic model for describing the release of ATD from the microspheres.

Figure 11 gives plots of the fractional drug release as a function of the square root of time, and Table 6 shows the coefficients of correlation and dissolution rate constants of 2-Aminothiazole according to the models studied. We have noted that the fractional release of ATD is proportional to the square root of time during the short time as shown in Figure 11.

Figures 12, 13, 14, 15 and 16 represents the HixonCrowel mathematical modeling.

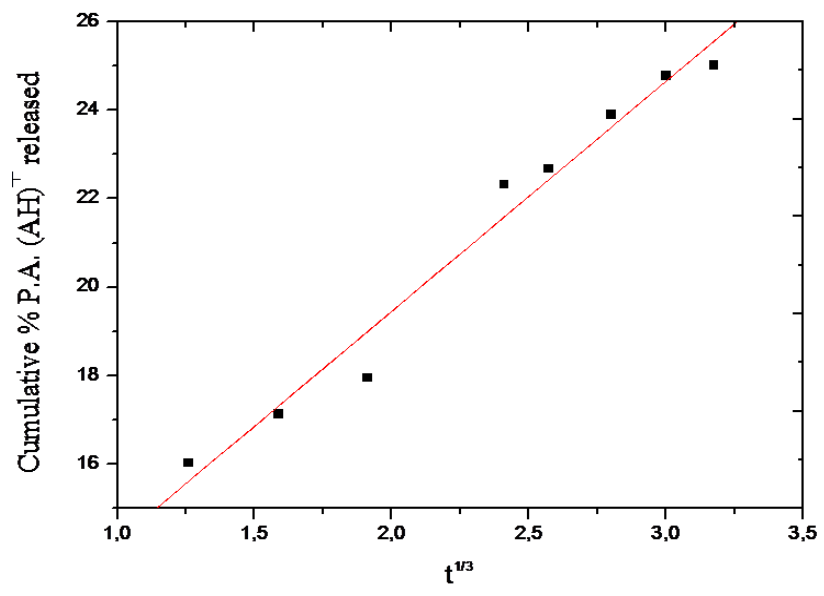

Figure 12: Hixon-Crowel plot of release rate from ECT6 microspheres

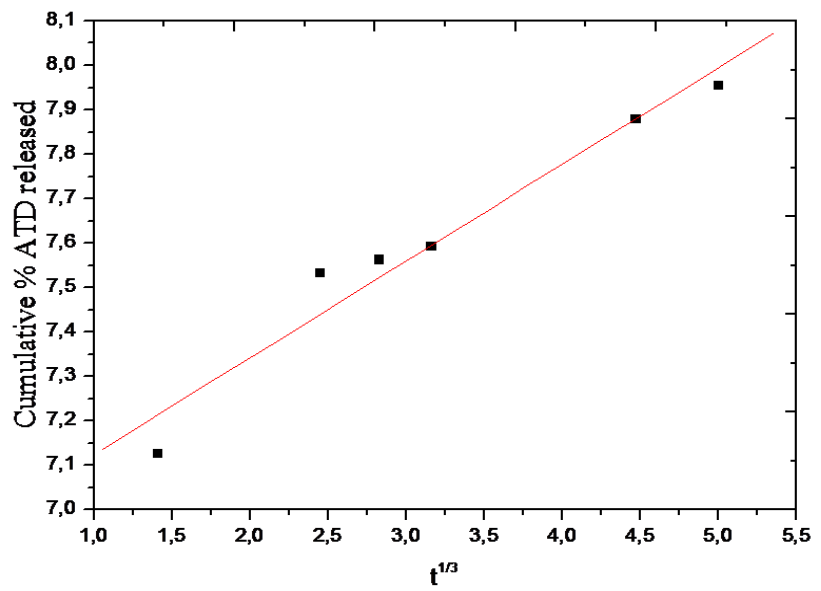

Figure 13: Hixon-Crowel plots of release rate from ECPVA4 microspheres 


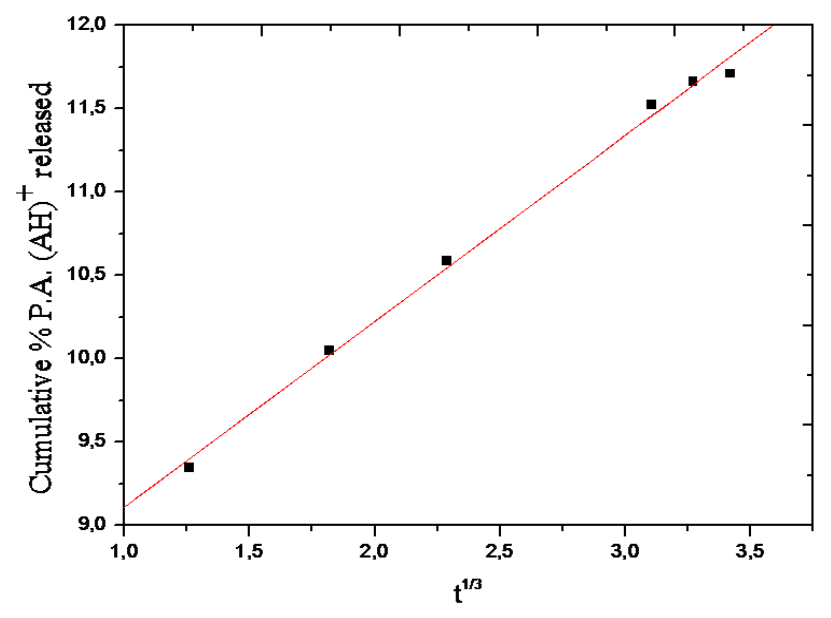

Figure 14: Hixon-Crowel plot of release rate from ECPVA6blades microspheres

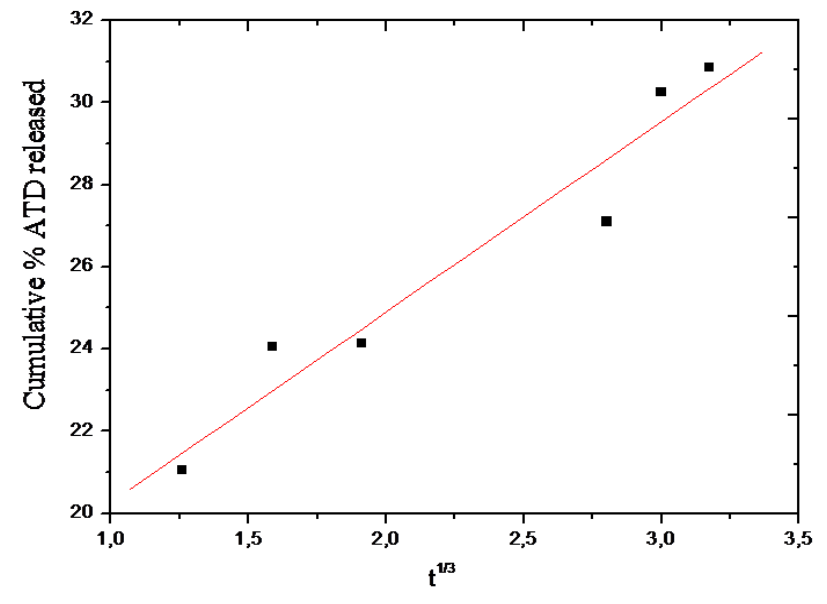

Figure 15: Hixon-Crowel plot of release rate from PBS microspheres

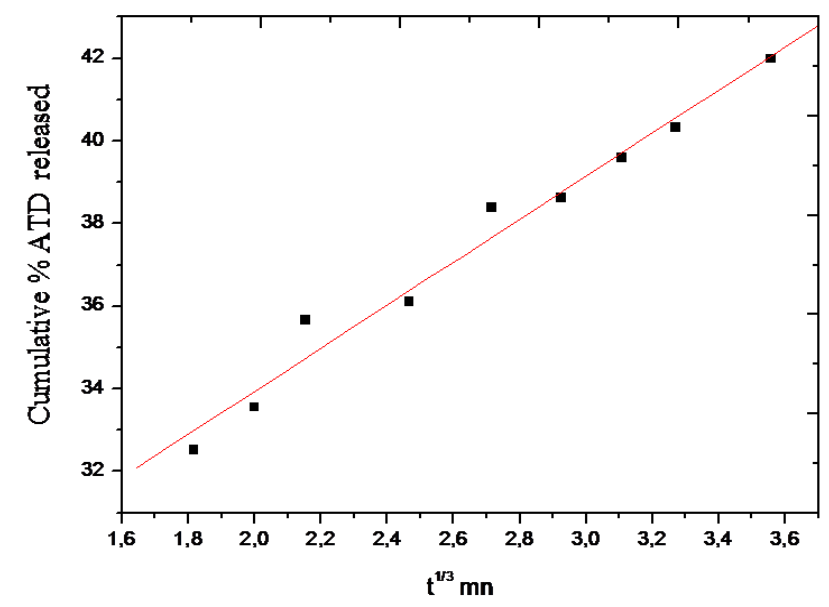

Figure 16: Hixon-Crowel plot of release rate from ECTween804blades microspheres

The suitable kinetics model for describing the release of ATD from misrospheres was the Higuchi model. The coefficients of correlation $\mathrm{r}^{2}$ in this model are above 0.96. From the results of Higuchi's equation plots, the dissolution rate constants of drug varied from 0.69031 $\min ^{-1 / 2}$ for PBS, $0.17406 \mathrm{~min}^{-1 / 2}$ for $\mathrm{EC}_{\mathrm{PVA}-4 \text { lades }}, 039283$ $\min ^{-1 / 2}$ for $\mathrm{EC}_{\text {PVA-6 blades }}, 2.48058 \mathrm{~min}^{-1 / 2}$ for $\mathrm{EC}_{\text {Tween80-4 }}$ blades to $0.12258 \mathrm{~min}^{-1 / 2}$ for $\mathrm{EC}_{\text {Tween80-6 blades. }}$. The effect of matrix on the dissolution rate is then notable.

\section{CONCLUSION}

This study was focused on the microencapsulation of 2-aminothiazole as an antithyroidian agent either by PBS as a biodegradable polyester matrix; which was synthesized and well characterized, its viscocimetric study was done too; and by ethylcellulose $\left(\mathrm{EC}_{10}\right)$ as a biocompatible polymer matrix in order to compare micro particles' characteristics (shape, size, dispersion, yield, efficiency, the drug release...). The formulation and the preparation of capsules were studied obeying to the European Pharmacopeia. Also, an important kinetic and mathematical study was been done in order to determine experimentally various release rates.

However, from these studies, we can conclude that the effects of emulsifiers and blades number as physicochemical parameters have a great impact on the characteristics of the elaborated micro particles(their quality, size, shape, their surface and morphology, the drug loaded...) and then certainly on the drug delivery of the active encapsulated agent. So, in this work all succeeded formulations conduct to a homogeneous spherical shape of micro particles. The only one succeeded formulation with PBS as a biodegradable polyester matrix is with 
PVA as an emulsifier and using 4 blades; this formulation conduct to a good dispersion but a low yield. In the other side, among the EC formulations the best one is well with PVA as an emulsifier and using 4 blades (unitary dispersion, good drug loaded as well as a good yield).

The drug releases are significantly influenced by the nature of matrix. Indeed, the kinetics of drug release obtained by experiment and theory are in good agreement, proving the validity of the chosen model. Diffusion, swelling and dissolution are the governing mechanisms involved in the overall drug release process. Finally, the practical advantage of the models is to identify the mechanism of drug release from our micro particles based on different biodegradable matrices to achieve desired release profiles, thus facilitating the development of a new microencapsulated prodrug.

\section{REFERENCES}

1. Kashiway $\mathrm{T}$, Hidaka $\mathrm{Y}$, Takano $\mathrm{T}$, Tatsumi $\mathrm{K}$, Izumi $\mathrm{Y}$, Shimaoka $\mathrm{Y}$ et al. Practical treatment with mininmum maintenance dose of antithyroid drugs for prediction of remission in graves' disease. Endoc J 2003;50(1):45-9. http:// dx.doi.org/10.1507/endocrj.50.45.

2. Smith $\mathrm{R}$, Oliver $\mathrm{C}$, Williams DF. The enzymatic degradation of polymers in vivo. J Biomed Mater Res. 1987;21(8):991-1003. http://dx.doi.org/10.1002/ jbm.820210805; PMid:2958461.

3. Wu L, Ding J. In vitro degradation of three-dimentional porous poly (D,L-lactide-co-glycolide) scaffolds for tissue engineering. Biomat. 2004;25(27):5821-30. http://dx.doi.org/10.1016/j.biomaterials.2004.01.038; PMid:15172494.

4. Middleton JC, Tipton AJ. Synthetic biodegradable polymers as orthopedic devices. Biomat. 2000;21(23):2335-46. http://dx.doi.org/10.1016/S01429612(00)00101-0.

5. Greenwald D, Shumway S, Albear P, Gottlieb L. Mechanical comparision of suture materials before and after In vivo incubation. J Surg Res. 1994;56(4):372-7. http://dx.doi.org/10.1006/jsre.1994.1058 ; PMid:8152233.

6. Nair LS, Laurencin CT. Biodegradable polymers as biomaterials. Prog. Polym. Sci. 2007;32:762-98.

7. Hickey T, Kreutzer D, Burguess D, Moussy F. In vivo evaluation of a dexamethasone/PLGA microsphere system designed to surpass the inflamatory tissue response to implantable medical devices. J Biomed Mat Res. 2002;61(2):180-7. http://dx.doi.org/10.1002/jbm.10016; PMid:12007197.

8. LeCorre P, Rytting J, Gajan V, Chevanne F, LeVerge R. In vitro controled release kinetics of local anesthetics from poly ( $D, L$-lactide) and poly(lactideco-glycolide) microspheres. J Microencap. 1997;14(2):243-55. http://dx.doi. org/10.3109/02652049709015336; PMid:9132474.

9. Ibim S. M, Ulrich KE, Bronson R, El-Amin SF, Langer RS, Lauencin CT. Poly(anhydrid-co-imide): In vivo biocompatibility in a rat model. Biomat. 1998;19(10):941-51. http://dx.doi.org/10.1016/S0142-9612(98)00019-2.

10. Ulrich KE, Ibim S M, Larrier DR, Langer RS, Lauencin CT. Chemical changes during In vivo degradation of poly(anhydrid-imides) matrices. Biomat. 1998;19(22):2045-50. http://dx.doi.org/10.1016/S0142-9612(98)00110-0.

11. Ibim SM, Ulrich KE, Attawia MA, Shastri VR, El-Amin SF, Bronson R et al. Preliinary In vivo report on osteocompatibility of poly(anhydride-co-imides) evaluated in a tibial model. J Biomed Mater Res. 1998;43(3):374-9. http://dx.doi. org/10.1002/(SICl)1097-4636(199824)43:4<374::AID-JBM5>3.0.CO;2-5.

12. Murthy RSR. Controlled and novel drug delivery. in: Jain N K (eds) CBS Publisher. New Dehi. 1997:27-51.

13. Phutane P, Shidhaye S, Lotlikar V, Ghule A, Sutar S, Kadam V. In vitro evaluation of novel sustained release microspheres ofglipizide prepared by the emulsion solvent diffusion-evaporation method. Pharma. 2010;2(1):35-41.
14. Wang SH, Zhang LC, Lin F, Sa XY, Zuo JB, Shao QX et al. Controlled release of levonorgestrel from biodegradable poly(D,L- lactide-co-glycolide) microspheres: in vitro and In vivo studie. Int J of Pharma. 2005;301(1):217-25. http://dx.doi.org/10.1016/j.ijpharm.2005.05.038 ; PMid:16040213.

15. Arshady R. Microencapsules for food. J of Microencap. 1993;10:413-35.

16. El Bahri Z, Taverdet JL. Preparation and optimization of 2,4-D loaded cellulose derivatives microspheres by solvent-evaporation technique, $\mathrm{J}$ of Applied Polym Science. 2007;103(4):2742-51. http://dx.doi.org/10.1002/ app.25488.

17. Diaf K, ElBahri Z, Chafi N, Belarbi L, Mesli A. Ethylcellulosepolycarolactone and eudragit matrices for controlled release of piroxicam from tablets and microspheres. Chem Papers. 2012;66(8):779-86. http://dx.doi.org/10.2478/ s11696-012-0191-x.

18. Thombre AG, Cardinal J. Encyclopedia of pharmaceutical technology. in: Swarbick J, Boylan J C (eds). Marcel Dekker, New York. 1990:61-88.

19. Freiberg S, Zhu XX. Polymer microspheres for controlled drug release. Int $\mathrm{J}$ of Pharma. 2004;282(1):1-18. http://dx.doi.org/10.1016/j.ijpharm.2004.04.013; PMid:15336378.

20. Lai MK, Tsiang RC. Encapsulating acetaminophen into poly(l-actide) microcapsules by solvent evaporation technique into an O/W emulsion. $\mathrm{J}$ of Microencap. 2004;21(3):307-16. http://dx.doi.org/10.1080/02652040410001 673928 ; PMid:15204597.

21. Le Core P, Le Guevello P, Gajan V, Chevanne F, Le Verge R. Preparation and characterization of bupivacaine-loadespolylactide and polylactideco-glycolyde microspheres, Int J of Pharma. 1994;107(1):41-9.

22. Chang TW, Huang YY, Liu YZ. Effects of the rate of solvent evaporation on the characteristics of drug loaded PLLA and PDLLA microspheres. Int $\mathrm{J}$ of Pharma. 2001;212(2):161-9. http://dx.doi.org/10.1016/S03785173(00)00574-3.

23. Duarte ARC, Costa MS, Simplicio AL, Cardoso MM, Duarte CMM. Preparation of controlled release microspheres using supercritical fluid technology for delivery of anti-inflammatory drugs. Int $\mathrm{J}$ of Pharma. 2006;308(1):168-74. http://dx.doi.org/10.1016/j.jpharm.2005.11.012 ; PMid:16368203.

24. Decker M. Ring Opening Polymerisation. New York: Fisch C K and Reegan L EDS.1969. PMCid:PMC1226634.

25. Guyot JC, Mathis C, Traisnel M, Verain A. Galénica 6 : Poudres et formes unitaires obtenues par agglomération ou division (Formes orales solides I). Paris : Technique et Documentation (Lavoisier). 1984.

26. Yunpeng $\mathrm{C}$, Yinghui $\mathrm{C}$, Xiaoyun $\mathrm{H}$, Zhenguo L, Weien Y. Porous microsphere and its applications. Int J Nanomedicine. 2013;8:1111-20.

27. Kim KK, Pack DW. Microspheres for drug delivery. Biological and Biomedical Nanotechnology. 2006;1(19-50). http://dx.doi.org/10.1007/978-0-387-258423_2.

28. Mouffok M, Mesli A, Abdelmalek I, Gontier E. Effect of formulation parameters on encapsulation efficiency and release bihavior of p-amino benzoic acidloaded ethylcellulose microspheres. J Serb Chem Soc. 2016;81:1-19.

29. Bhudian A, Siegel SJ, Winey KI. Controlling the in vitro release profiles for a system of haloperidol-loaded PLGA. Int J of Pharmaceutics. 2008;346(1):151-9. http://dx.doi.org/10.1016/j.jpharm.2007.06.011; PMid:17681683.

30. Muheem A, Shakeel F, Jahangir MA, Anwar M, Mallick N, Jain GK, Warsi MH, Ahmad FJ. A review on the strategies for oral delivery of proteins and peptides and their clinical perspectives. Saudi Pharmaceutical Journal. 2016;24:413-28. http://dx.doi.org/10.1016/j.jsps.2014.06.004; PMid:27330372 PMCid: PMC4908063.

31. Zhu Z, Zhai Y, Zhang N, Leng D, Ding P. The development of polycarbophil as a bioadhesive material in pharmacy. Asian Journal of Pharmaceutical Sciences. 2013;8(4):218-27. http://dx.doi.org/10.1016/j.ajps.2013.09.003.

32. da Silva AR, Zaniquelli MED, Baratti MO, Jorge RA. Drug release from microspheres and nanospheres of poly(lactide-co-glycolide) without sphere separation from the release medium. J Braz Chem Soc. 2010;21(2):214-25.

33. Zang Z, Sun A, Long L. Effect of physicochemical properties of drugs on morphology and release of microspheres. J of Med and Biol Eng. 2013;3(4):293-8.

34. Kalam MA, Humayum M. et al, Release kinetics of modified pharmaceutical dosage forms: a review". Continental J Pharmaceutical Sciences. 2007;1:30-5.

35. Higuchi, T., Mechanism of sustained-action medication. Theoretical analysis of rate ofrelease of solid drugs dispersed in solid matrices. Journal 
Pharmaceutical Sciences. 1963;52(12):1145-9. http://dx.doi.org/10.1002/ jps.2600521210.

36. Hixson AW, Crowell JH. Dependence of reaction velocity upon surface and agitation. Ind Eng Chem. 1931;23(10):923-31. http://dx.doi.org/10.1021/ ie50262a025 : http://dx.doi.org/10.1021/ie50260a018.

37. Costa P, Lobo JMS. Modeling and comparison of dissolution profiles. Eur J Pharm Sci. 2001;13(2):123-33. http://dx.doi.org/10.1016/S09280987(01)00095-1.

38. Tanaka N, Imai K, Okimoto K, Ueda S, Tokunaga Y, Ohike A, et al. Development of novel sustained-release system, disintegration-controlled matrix tablet
(DMCT) with solid dispersion granules of nilvadipine. J Control Release. 2005,108(2):386-96. http://dx.doi.org/10.1016/j.jconrel.2005.08.024; PMid:16253377.

39. Korsmeyer R, Gurny W, Doelker R, Buri E, Peppas P NA. Mechanisms of solute release from porous hydrophilic polymers. International Journal of Pharmaceutics. 1983;15(1):25-35. http://dx.doi.org/10.1016/0378-5173 (83)90064-9.

40. Siepmann J, Peppas NA. Modeling of drug release from delivery systems based on hydropropyl methylcellulose (HPMC). Adv Drug Deliv Rev. 2001;48(2):139-57. http://dx.doi.org/10.1016/S0169-409X(01)00112-0.

\section{PICTORIAL ABSTRACT}
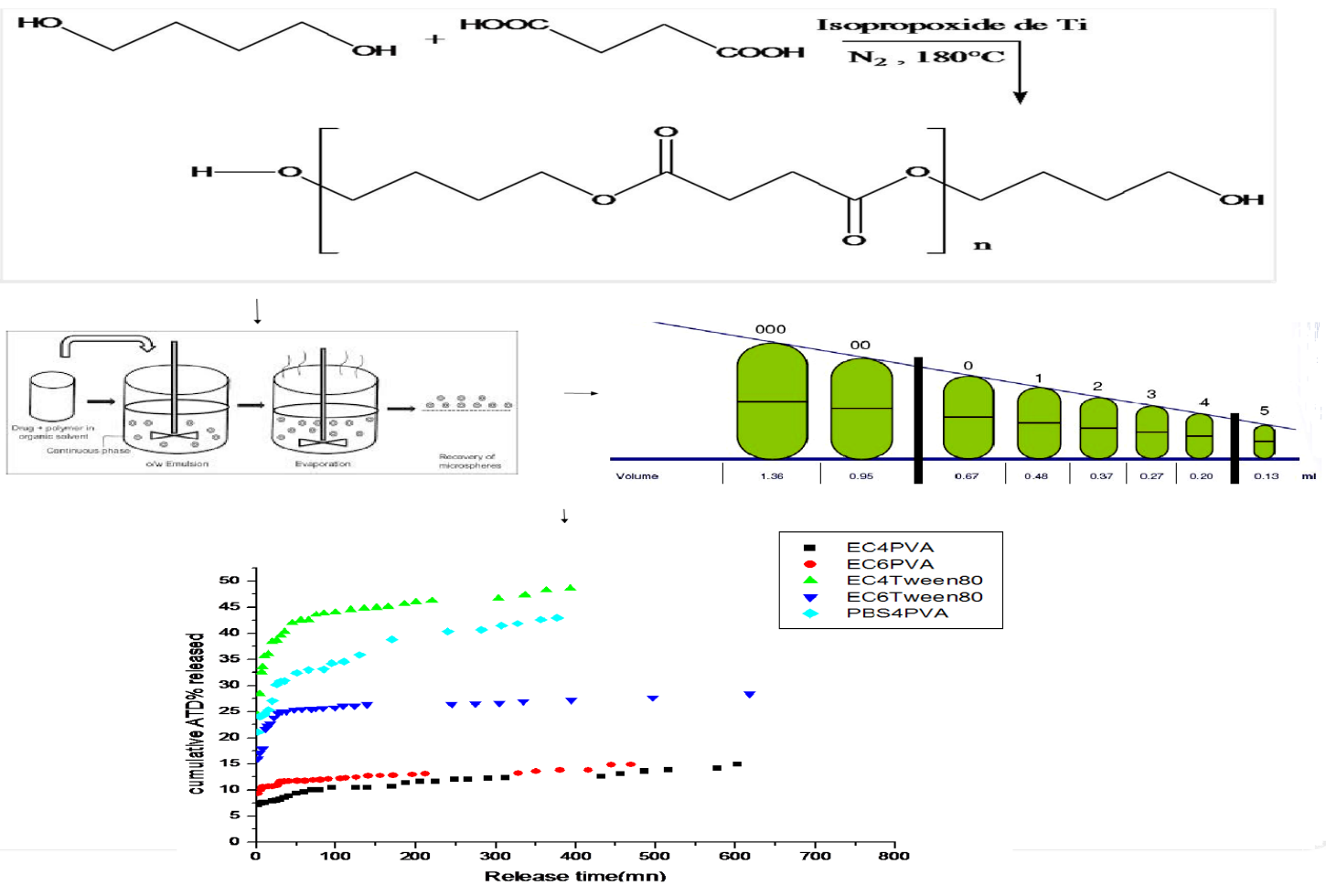

\section{SUMMARY}

- In order to modify the release late of our antithyroid agent several microspheres' formulations have been done according to the solvent-evaporation microencapsulation method. In this axe, a study of the effect of some physico-chemical parameters on formulations was done.

- In order to eliminate any source of toxicity we have synthesized and well characterized a biodegradable polyester which we used as matrix for microencapsulation. As well as we have used Ethyl cellulose as a biocompatible polymer matrix

- Elaborated microspheres were well characterized where we calculated the mean diameters and size distribution of microparticles from results of optical microscopy. Best formulations were then marked.

- A kinetic study of the drug delivery was done in gastric $\mathrm{pH}$ at $37^{\circ} \mathrm{C}$ in order to evaluate the late effect and to determine a sustained delivery. All deliveries obey to a Fickian order and are determined by a diffusional step.

- Theoretical analyses of drug release kinetics have been established and 2-aminothiazole dissolution rate constants were calculated from Higuüchi's and Hixon-Crowel's release models. The suitable kinetics model for describing the release of ATD from misrospheres was the Higuchi model. The practical advantage of the models is to identify the mechanism of drug release from our microparticles based on different biodegradable matrices to achieve desired release profiles, thus facilitating the development of a new microencapsulated prodrug.

- The formulation and the preparation of capsules were studied obeying to the European Pharmacopeia. 


\section{About Authors}

Soumia CHIRANI: Assistant Professor in the Department of Pharmacy, Faculty of Medical Sciences, University Djillali LIABES of Sidi Bel-Abbes, ALGERIA. Researcher member in Laboratory of Organic Physical and Macromolecular Chemistry, in Exact Sciences Faculty, University Djillali LIABES of Sidi Bel-Abbes, ALGERIA.

Mohammed Oussama LEBIG: Doctorant member in Laboratory of Organic Physical and macromolecular Chemistry, Faculty of Exact Sciences, University DjillaliLiabes of SidiBel-Abbes, Algeria.

Sarah BOUAMEUR: Assistant Professor in the Department of Pharmacy, Faculty of Medical Sciences, University Djillali LIABES of Sidi Bel-ABBES. Researcher in Galenic Laboratory, Department of Pharmacy, Faculty of Medical Sciences, University Djillali LIABES of Sidi Bel-ABBES

Meriyem MOUFFOK: Doctorant member in Laboratory of Organic Physical and macromolecular Chemistry, Faculty of Exact Sciences, University DjillaliLiabes of SidiBel-Abbes, Algeria.

Naziha CHIRANI: Doctoral post researcher in Laboratory of Innovation and BioperformanceAnalyse -LIAB, Polytechnic School, University of Montreal Quebec, Canada. Confrence professor in Department of Chemistry, Faculty of Exact Sciences, University DjillaliLiabes of SidiBel-Abbes, Algeria

Nafa CHAFI: Professor in Department of Chemistry, Faculty of Exact Sciences, University DjillaliLiabes of SidiBelAbbes, Algeria. Researches Chef mumber in Laboratory of Organic Physical and Macromolecular Chemistry, Faculty of Exact Sciences, University DjillaliLiabes of SidiBel-Abbes, Algeria.

Kaddour GUEMRA: Professor in Department of Chemistry, Faculty of Exact Sciences, University DjillaliLiabes of SidiBel-Abbes, Algeria Researches Chef member inLaboratory of Organic Physical and Macromolecular Chemistry, Faculty of Exact Sciences, University DjillaliLiabes of SidiBel-Abbes, Algeria.

Cite this article : Chirani S, Lebig MO, Bouameur S, Mouffok M, Chirani N, Chafi N, Guemra K. Elaboration of Microspheres' Capsules Based on Ethylcellulose and Synthesized Poly (Butylsuccinate) as Biodegradable Matrices for Drug Delivery of an Antithyroidian Agent. Indian J of Pharmaceutical Education and Research. 2017;51(2s):S79-S90. 